\title{
Progress in familial hypertrophic cardiomyopathy: molecular genetic analyses in the original family studied by Teare
}

\author{
Hugh Watkins, C E Seidman, Calum MacRae, J G Seidman, William McKenna
}

In this journal in 1958 Donald Teare reported the pathological findings in a series of eight unrelated young adults who died suddenly and who at necropsy had manifested gross asymmetrical hypertrophy of the heart. ${ }^{1}$ In a footnote, he noted the recent sudden death of the brother of one of the original cases, thus identifying the familial nature of this condition. The subsequent report $^{2}$ of two generations of the family of these two siblings showed that asymmetrical hypertrophy was inherited in a manner consistent with an autosomal dominant trait. The term "obstructive cardiomyopathy" was proposed for these and similar cases, identifying this as a heart muscle disorder. The description of this family initiated the detailed characterisation of this novel syndrome, which was later called familial hypertrophic cardiomyopathy.

Demonstration of a mendelian form of inheritance implied that familial hypertrophic cardiomyopathy was the result of a single gene disorder. Despite 30 years of investigation, however, the pathogenesis of this condition is only now being revealed. Molecular biological techniques were used to identify first the location $^{3}$ and later the identity ${ }^{45}$ of genetic defects responsible for familial hypertrophic cardiomyopathy. The identification of mutations in the cardiac myosin heavy chain (MHC) genes has made familial hypertrophic cardiomyopathy the first primary cardiac disorder to be characterised at the molecular level. An abnormality of the $\beta$ myosin heavy chain gene is also responsible for disease in the original family described by Teare; we discuss here the benefits of such a genetic diagnosis.

\section{Background}

The clinical genetics of familial hypertrophic cardiomyopathy were established by the observation of inheritance patterns in families such as the one described here. Since the advent of cross sectional echocardiography it has been clear that, where the familial condition is familial, it is inherited as an autosomal dominant trait. In a significant minority of cases, hypertrophic cardiomyopathy occurs as an apparently sporadic condition. ${ }^{67}$ Cases of sporadic disease are defined as those where no first degree relatives are known to be affected. The frequency of such cases will tend to be overestimated by failure to identify subtle forms of the condition in relatives, especially children, of the proband. In many families expression of the disease gene is such that ${ }^{\circ}$ penetrance is virtually complete in adults. This $\vec{\circ}$ is usually not the case in children, however, where the phenotype frequently does not $\vec{\omega}_{\tilde{O}}$ become manifest until adolescence, ${ }^{8}$ or in some $\supsetneq$ families where subclinical disease is present. Until a definitive genetic diagnosis is available ? the full range of the disease phenotype and the $\vec{\omega}$ extent and nature of sporadic disease will remain uncertain.

Recent advances in molecular biology have $\vec{c}$ led to the identification of the gene defects responsible for several important inherited conditions, even where there was no prior knowledge of any defect at the protein level $\vec{\bullet}$ (reviewed in reference ${ }^{9}$ ). In the absence of any apparent candidate genes or of any known cytogenetic abnormality in familial hypertrophic cardiomyopathy, the approach that was adopted was the use of linkage analysis. Linkage analysis depends upon the demonstration of "co-segregation" of a disease trait with a DNA polymorphism of known chromosomal location. If a DNA polymorphism is situated close to the disease gene on a given chromosome, then the presence of the polymorphism at this site will tend to be inherited with the disease trait in a family pedigree. Where a polymorphism and a disease gene are separated by some distance they will tend to become separated by crossovers, or recombinations, during meiois. Thus the extent of co- 을 inheritance, or co-segregation, within a $\frac{D}{O}$ pedigree defines the closeness of linkage. Linkage analyses were performed in a large $\tilde{\sigma}$ French Canadian family with familial hyper- $N$ trophic cardiomyopathy to test systematically a N panel of probes that identify polymorphic loci on all chromosomes, until one was found that identified a locus that co-segregated with disease. This search revealed that the gene for $\stackrel{\oplus}{\rightleftharpoons}$ familial hypertrophic cardiomyopathy in this 0 family was on chromosome 14 , in the region of the genes for the cardiac myosin heavy chains ( $\alpha$ and $\beta$ cardiac MHC genes). ${ }^{310}$

Myosin heavy chains are the major structural component of heart muscle, and so were clearly potential candidates for involvement in this disease. The demonstration of a major gene $\bar{c}$ rearrangement affecting the $\alpha$ and $\beta$ MHC genes in one family ${ }^{4}$ led to the hypothesis that the MHC genes were indeed the site of mutations causing disease in familial hypertrophic cardiomyopathy. No such rearrangement was found in the original French Canadian family, 
Figure 1 Family pedigree. (a) Original pedigree as depicted by Hollman, Goodwin

Teare, and Renwick. (b) Current pedigree showing the subject number and disease status of family members. Squares are male family members and circles female. Solid symbols are those with hypertrophic

cardiomyopathy, open symbols are those unaffected and hatched symbols are those not examined. Those who have died are indicated by an oblique stroke. Members of generations I and II were those described in the original account of this family, with individuals $I I-1$ and II- 2 being the presenting cases. Since the 1960 report four of the six surviving affected members have died; one of the two remaining survivors is undergoing transplant assessment. Of the four affected members of generation III one has died and one has been resuscitated from an out of hospital cardiac arrest.

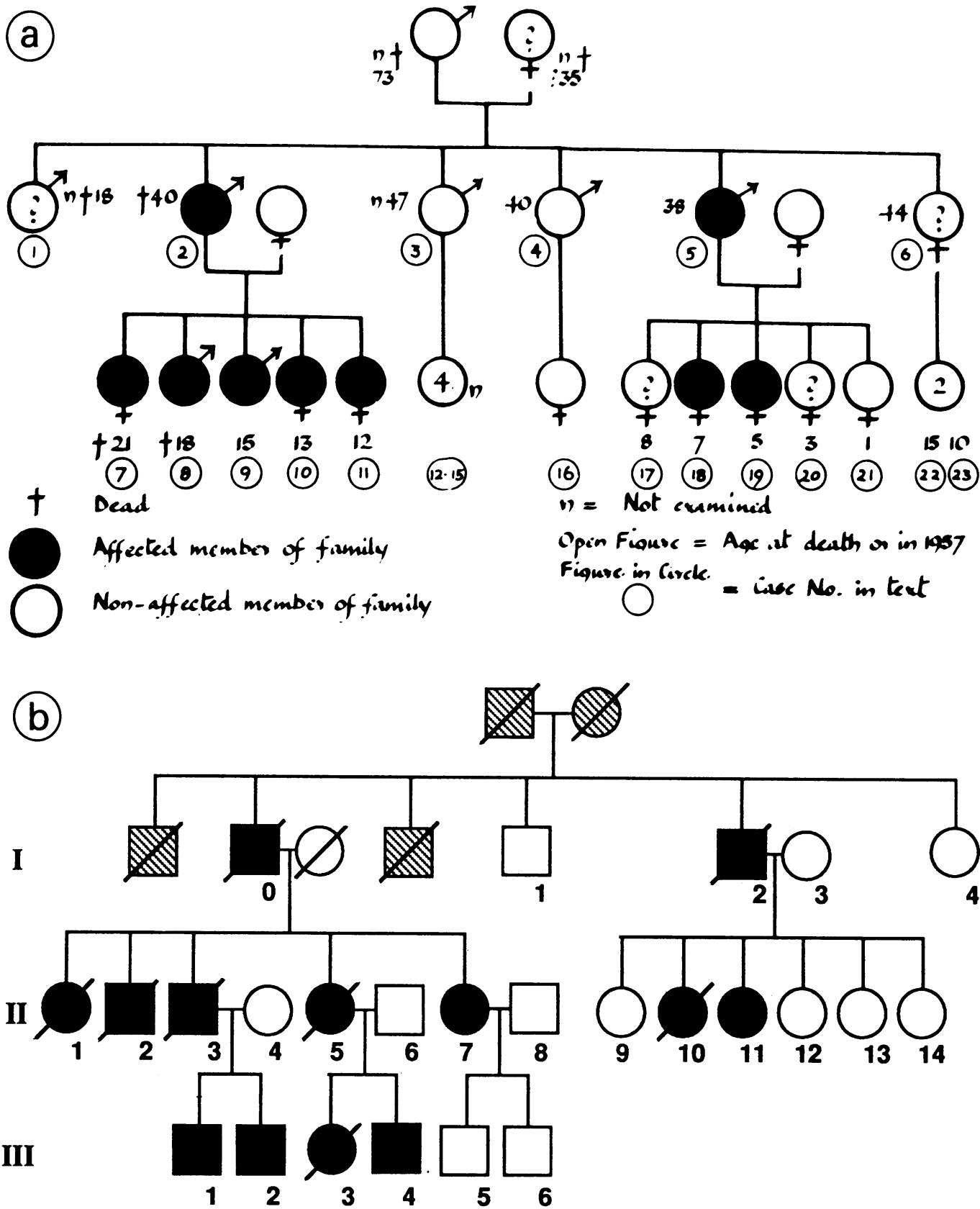

thus necessitating a detailed search for a point mutation. Each of the MHC genes contains approximately 30000 nucleotides, making identification of a single base pair substitution very difficult. Such a mutation, however, was identified in exon 13 of the $\beta$ cardiac MHC gene in this family, that results in the conversion of a highly conserved arginine residue to a glutamine residue. ${ }^{5}$

These findings have generated several further questions. In particular, linkage data have shown that not all familial hypertrophic cardiomyopathy can be attributed to MHC mutations on chromosome $14 .^{11}$ However, conventional linkage analyses are frequently uninformative in smaller families and so have not detailed the proportion of familial hypertrophic cardiomyopathy that results from myosin mutations. Also, the two described mutations implicate different mechanisms for the pathogenesis of the autosomal dominant phenotype. Studies were therefore undertaken to document the presence of myosin mutations in other families with familial hypertrophic cardiomyopathy. As in the French Canadian family, no major rearrangements or deletions were found in the MHC genes of 40 unrelated families with familial hypertrophic cardiomyopathy, suggesting that point mutations were likely to be the predominant mutations causing disease (Tanigawa et al. Unpublished). This finding led to the development of a screening technique for analysing the protein coding section of the $\beta$ MHC gene for sequence abnormalities. Such polymorphisms can be used to detect linkage to the MHC locus and, if they are linked they are excellent candidates for being disease-causing mutations. The success of this technique is illustrated by its application to the original Teare family.

\section{Clinical evaluation}

Not surprisingly the family with familial hypertrophic cardiomyopathy that first came to medical attention was one with particularly 
Clinical findings in affected family members

\begin{tabular}{|c|c|c|c|c|c|c|c|c|c|c|}
\hline $\begin{array}{l}\text { Pedigree } \\
\text { number }\end{array}$ & $\begin{array}{l}\text { Age at } \\
D / F U\end{array}$ & $\begin{array}{l}\text { Chest } \\
\text { pain }\end{array}$ & $\begin{array}{l}\text { Dyspnoea } \\
(N Y H A)\end{array}$ & Syncope & $\begin{array}{l}\text { Abnormal } \\
\text { ECG }\end{array}$ & AF/emboli & $L V H$ & $R V H$ & $\begin{array}{l}\text { LVOT } \\
\text { gradient }\end{array}$ & $\begin{array}{l}\text { Clinical } \\
\text { events }\end{array}$ \\
\hline $\begin{array}{l}\text { I-0 } \\
\text { I-2 } \\
\text { II-1 } \\
\text { II-2 } \\
\text { II-3 } \\
\text { II-5 } \\
\text { II-7 } \\
\text { II-10 } \\
\text { II-11 } \\
\text { III-1 } \\
\text { III-2 } \\
\text { III-3 } \\
\text { III-4 }\end{array}$ & $\begin{array}{l}40 / M \\
52 / M \\
21 / F \\
18 / M \\
42 / M \\
32 / F \\
45 / F \\
20 / F \\
39 / F \\
24 / M \\
22 / M \\
23 / F \\
22 / M\end{array}$ & $\begin{array}{l}+ \\
+ \\
+ \\
- \\
+ \\
- \\
- \\
- \\
- \\
- \\
+ \\
+\end{array}$ & $\begin{array}{l}\text { III } \\
\text { II } \\
\text { III } \\
\text { I } \\
\text { III } \\
\text { III } \\
\text { III } \\
\text { II } \\
\text { II } \\
\text { I } \\
\text { I } \\
\text { III } \\
\text { II }\end{array}$ & $\begin{array}{l}\bar{t} \\
\overline{+} \\
+ \\
+ \\
\bar{t} \\
\overline{+} \\
\overline{+} \\
+ \\
+\end{array}$ & $\begin{array}{l}+ \\
+ \\
+ \\
+ \\
+ \\
+ \\
+ \\
+ \\
+ \\
+ \\
+ \\
+ \\
+\end{array}$ & $\begin{array}{l}- \\
\overline{-} \\
\overline{-} \\
+ \\
\overline{-} \\
\overline{-} \\
\overline{+} \\
\overline{+} \\
+\end{array}$ & $\begin{array}{l}530 \mathrm{~g} \\
- \\
450 \mathrm{~g} \\
425 \mathrm{~g} \\
- \\
\overline{17} \mathrm{~mm} \\
490 \mathrm{~g} \\
13 \mathrm{~mm} \\
14 \mathrm{~mm} \\
13 \mathrm{~mm} \\
20 \mathrm{~mm} \\
25 \mathrm{~mm}\end{array}$ & $\begin{array}{l}+ \\
\overline{+} \\
\overline{+} \\
+ \\
\overline{+} \\
+ \\
+ \\
+ \\
\overline{+}\end{array}$ & $\begin{array}{l}- \\
\overline{+} \\
\overline{+} \\
+ \\
\overline{+} \\
+ \\
\overline{+} \\
+ \\
+ \\
+\end{array}$ & $\begin{array}{l}\text { Sudden death } \\
\text { Sudden death } \\
\text { Sudden death } \\
\text { Sudden death } \\
\text { Died awaiting transplant } \\
\text { Died CHF } \\
\text { Transplant assessment } \\
\text { Sudden death } \\
\text { Alive } \\
\text { AF } \rightarrow \text { circulatory collapse } \\
\text { Out of hospital VF } \\
\text { Died after myomectomy } \\
\text { Alive }\end{array}$ \\
\hline
\end{tabular}

AF, atrial fibrillation; Age at D/FU, age at death or current follow up; CHF, congestive heart failure; LVH, left ventricular hypertrophy cited as cardiac weight at necropsy or maximum LV wall thickness on echocardiography; LVOT gradient, LV outflow tract gradient at catheterisation or the presence of systolic anterior motion of the mitral valve on echocardiography; RVF, right ventricular hypertrophy; VF, ventricular fibrillation.

severe disease, enabling Hollman et al to make a remarkably complete account of the range of symptoms, signs, findings on investigation, and complications of this condition. ${ }^{2}$ Thus the high incidence of sudden death, progressive heart failure, and cerebral embolus was identified. The presence of "extensive scattered fibrosis" was described and considered to be a possible anatomical basis for ventricular fibrillation. Hollman et al noted that the unifying pathological features were more consistent within this condition than the clinical features were within the one family.

Thirty-two years of follow up data are now available on this family (fig 1 , table 1 ). While there is a range of disease severity, this is a family with an especially malignant natural history. Of 13 affected individuals six died suddenly or experienced an out of hospital cardiac arrest. Another has been successfully resuscitated from acute circulatory collapse associated with the onset of atrial fibrillation. Six of these seven individuals were symptomfree before their premature sudden cardiac death, which occurred at ages between 18 and 52 years. Those who have died suddenly had mild to moderate myocardial hypertrophy but considerable myocyte and myofibrillar disarray with extensive myocardial fibrosis.

Faced with such a severe disease there was a move to undertake myomectomy, partly in an attempt to modify prognosis, in addition to controlling symptoms attributable to obstruction of the left ventricular outflow tract. Two of those who underwent myomectomy (II-3 II-5) died in congestive heart failure shortly afterwards (one while awaiting transplantation) while the third patient died (III-3) in a high output state within hours of operation for severe mitral regurgitation and left ventricular outflow obstruction. This individual had been on long term amiodarone treatment before operation for paroxysmal atrial fibrillation associated with generalised seizures.

\section{Molecular studies}

The molecular genetic techniques devised to screen for $\beta$ MHC mutations have been described in detail elsewhere. ${ }^{12}$ In brief, segments of DNA from the $\beta$ cardiac MHC genes of an affected individual are amplified in vitro by the polymerase chain reaction. These products are analysed in an RNase protection assay which identifies mismatches between patient DNA and a normal control sequence. The entire coding sequence (approximately 6000 base pairs) can be examined, in sections of up to 500 base pairs at a time. DNA extracted from peripheral leucocytes of individual III-2 was
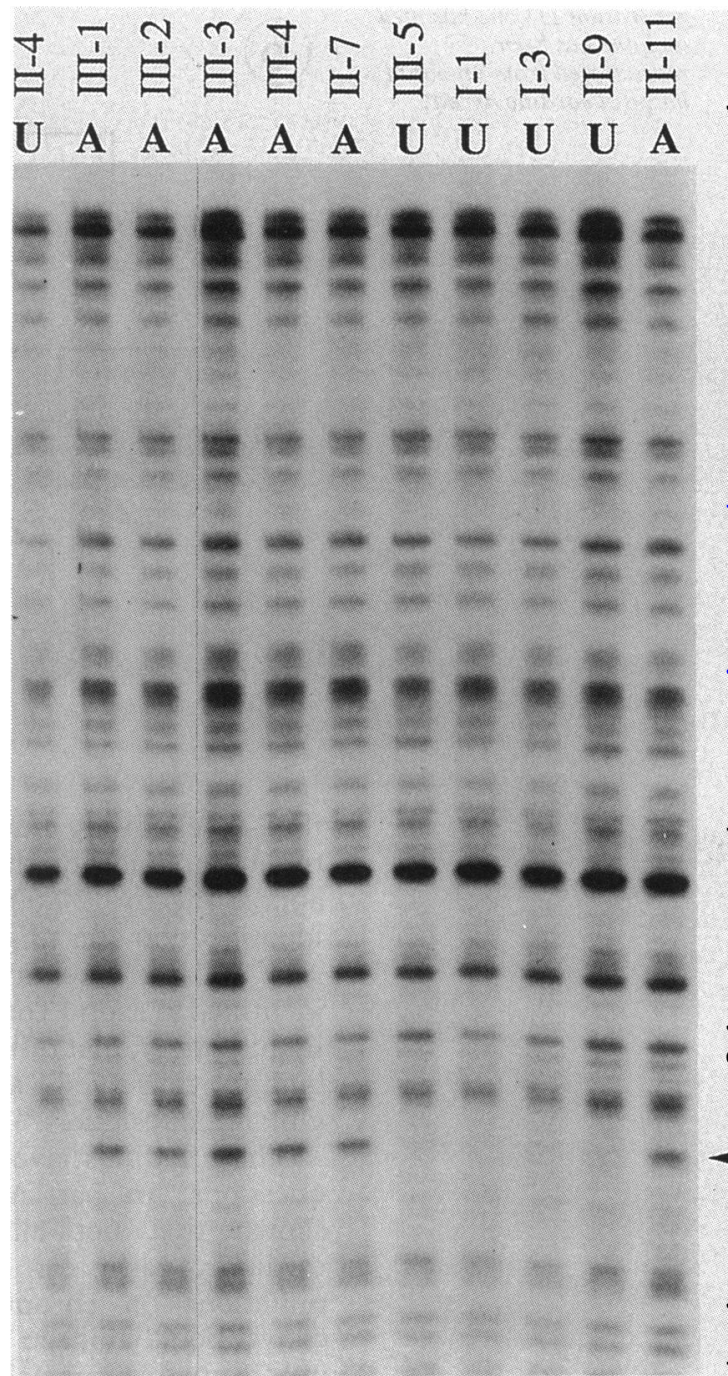

Figure 2 Detection of a sequence mismatch in exon 14 in affected family members. An RNase protection assay of exon 14 is shown. DNA samples from unaffected (U) and affected $(A)$ individuals are identified by pedigree number. The assay showed an abnormal fragment (arrowed) that was present only in affected individuals. This fragment indicates cleavage of the normal RNA probe sequence because of a sequence mismatch with the DNA from affected individuals. 
screened in this way. The analysis showed evidence of a sequence mismatch in exon 14 in this individual. A similar analysis of the remaining family members showed this abnormality in all affected members (fig 2). In contrast, this mismatch was not present in unaffected family members. The association of this abnormality in myosin with the disease shows linkage of the familial hypertrophic cardiomyopathy trait to the MHC locus in this family, with a LOD score (logarithm of the odds) of 3.9 (odds of almost 10000 to 1 in favour of linkage).

This abnormality in exon 14, which shows complete concordance with disease status throughout the family and which to date has not been seen in unaffected individuals, is the likely candidate for being the disease-causing mutation. Further characterisation of this defect will establish the precise abnormality in MHC gene and its polypeptide structure.

\section{Implications of genetic diagnosis}

The detection of an abnormality within the $\beta$ myosin heavy chain gene in a family such as this makes the subsequent diagnosis of disease state very simple in any family member. The diagnosis can be made definitively in children and adolescents in these families and also in those adults who are difficult to diagnose clinically. ${ }^{12}$ Similarly, unaffected individuals can be told with certainty that they and their offspring will remain free of the condition, thereby avoiding the need for serial clinical screening. Although the surviving members of this family all have had correctly assigned clinical diagnoses it is noteworthy that sudden death has been the presenting feature in this family in the past. As members of generation III approach reproductive age it is now possible to screen their offspring and establish the diagnosis at any stage.

A genetic diagnosis made preclinically or even prenatally identifies individuals at risk of the complications of familial hypertrophic cardiomyopathy before the development of clinically detectable abnormalities. For the first time, it is now possible to study the natural history before established hypertrophy or complications of familial hypertrophy cardiomyopathy develop. This means that treatment can be started early and its effects on the disease process or its consequences can be studied longitudinally. In particular, individuals identified in this way as having familial hypertrophic cardiomyopathy can be assessed for risk factors for sudden death to allow for appropriate interventions. It is hoped that early diagnosis and use of existing treatment will already be sufficient to reduce the burden of the disease in families such as the one described here. Perhaps more importantly, the opportunity to perform prospective trials of intervention early in the course of familial hypertrophic cardiomyopathy should generate even more effective treatment in the future.

It is also expected that knowledge of the genetic basis of familial hypertrophic cardiomyopathy in a family or an individual may provide more than a means of definitive diagnosis-by also providing a prognostic indicator. There is considerable variability in the severity of familial hypertrophic cardiomyopathy among different families, with some (such as the family Teare studied) showing far greater morbidity and mortality than others. ${ }^{13-15}$ Despite the acknowledged variability of expression within a given family, ${ }^{16}$ such trends that characterise a particular family are most likely to result from the influence of the specific disease-causing mutation. As more disease-causing mutations are identified, a genetic classification is becoming available for some familial hypertrophic cardiomyopathy families, so that it is now possible to begin determining the influence of the type of mutation on the natural history (Watkins et al. Unpublished). The clinical features of unrelated families sharing a particular mutation can be compared with those of individuals with different mutations within the MHC genes and with those with non-myosin defects, to detect any predictive associations with particular mutation types.

In conclusion, genetic diagnosis in an individual or in a family is becoming a practical proposition and is likely to affect profoundly the management of this condition, both in terms of early diagnosis and risk stratification. Identification of the remaining disease-causing gene(s) in familial hypertrophic cardiomyopathy may be possible by investigating the genes for other cardiac contractile proteins. A complete genetic classification will then be available to determine the full spectrum of manifestations of familial hypertrophic cardiomyopathy. Unresolved issues such as the nature of apparently similar clinical syndromes ${ }^{17}$ and the frequency and origins of sporadic disease, will be clarified. Moreover, in addition to the expected clinical benefits of these findings, the documentation of disease-causing mutations in the $\beta$ cardiac MHC gene will provide insights into myosin structure-function relations that will have impact in wider areas of basic science research.

This work would not have been possible without the cooperation of the family members. We thank K Adams, S Dickie, and A O'Donoghue for help collecting family data. This work was supported by grants from the British Heart Foundation (HW and WM; HW is the recipient of a British Heart Foundation Clinical Scientist Fellowship), National Institutes of Health (HL46320 to JGS, HL41474 and HL42467 to CES) Howard Hughes Medical Foundation (JGS), the American Heart Association (CES), and Bristol Myers Squibb Company.

1 Teare D. Asymmetrical hypertrophy of the heart in young adults. Br Heart $J$ 1958;20:1-8.

2 Hollman A, Goodwin JF, Teare D, Renwick JW. A family with obstructive cardiomyopathy (asymmetrical hypertrophy). Br Heart J 1960;22:449-56.

3 Jarcho JA, McKenna W, Pare JA, et al. Mapping a gene for familial hypertrophic cardiomyopathy to chromosome 14q1. N Engl J Med 1989;321:1372-8.

4 Tanigawa G, Jarcho JA, Kass S, et al. A molecular basis for familial hypertrophic cardiomyopathy: an alpha/beta cardiac myosin heavy chain hybrid gene. Cell 1990; 62:991-8.

5 Geisterfer-Lowrance AA, Kass S, Tanigawa G, et al. A molecular basis for familial hypertrophic cardiomyopathy: a beta cardiac myosin heavy chain gene missense mutation. Cell 1990;62:999-1006.

6 Greaves SC, Roche AHG, Neutze JM, Whitlock RML, Veale AMO. Inheritance of hypertrophic cardiomyopathy: a cross sectional and $M$ mode echocardiographic study of 50 families. Br Heart J 1987;58:259-66.

7 Maron BJ, Nichols PF, Pickle LW, Wesley YE, Mulvihill JJ. Patterns of inheritance in hypertrophic cardiomyopathy: 
assessment by M-mode and two-dimensional echocardiography. Am J Cardiol 1984;53:1087-94.

8 Maron BJ, Spirito P, Wesley YE, Arce J. Development and progression of left ventricular hypertrophy in children with hypertrophic cardiomyopathy $N$ Engl J Med 1986; 315:610-4.

9 Antonarakis SE. Diagnosis of genetic disorders at the DNA level. $N$ Engl J Med 1989;320:153-63.

10 Solomon SD, Geisterfer-Lowrance AA, Vosberg HP, et al. A locus for familial hypertrophic cardiomyopathy is closely linked to the cardiac myosin heavy chain genes, CRI-L436, and CRI-L329 on chromosome 14 at q11-q12. Am J Hum Genet 1990;47:389-94.

11 Solomon SD, Jarcho JA, McKenna W, et al. Familia hypertrophic cardiomyopathy is a genetically heterogeneous disease. J Clin Invest 1990;86(3):993-9.

2 Rosenzweig A, Watkins H, Hwang D-S, et al. Preclinical diagnosis of familial hypertrophic cardiomyopathy by genetic analysis of blood lymphocytes. $N$ Engl J Med 1991;325:1753-60.
13 Maron BJ, Lipson LC, Roberts WC, Savage DD, Epstein SE. "Malignant" hypertrophic cardiomyopathy: identification of a subgroup of families with unusually frequent premature death. Am J Cardiol 1978;41:1133-40.

14 McKen $W$, trophic cardiomyopathy: role of age and clinical electrrophic cardiomyopathy: role of age and clinical, electrocardiographic and haemodynamic features. Am J Cardiol

15 Maron BJ, Bonow RO, Cannon RO, Leon MB, Epstein SE. Hypertrophic cardiomyopathy: interrelations of clinical manifestations, pathophysiology, and therapy. $N$ Engl J 1987:316:780-89 and 844-52.

16 Ciro E, Nichols PF, Maron BJ. Heterogeneous morphologic expression of genetically transmitted hypertrophic cardiomyopathy: two-dimensional echocardiographic analysis. Circulation 1983;67:1227-33.

17 McKenna WJ, Stewart JT, Nihoyannopoulos P, et al. Hypertrophic cardiomyopathy without hypertrophy: two families with myocardial dissarray in the absence of increased myocardial mass. Br Heart $J$ 1990;63:287-90.

\section{ABSTRACTS IN CARDIOLOGY}

\section{Big people and big hearts}

Many echocardiographic examinations and most necropsy reports adopt an arbitrary upper limit for left ventricular mass (allowing a difference for sex) to define the presence of hypertrophy. They do not make adequate allowance for the variation in body size.

Left ventricular mass correlates strongly with body height as was well shown in a previous Framingham study by Levy and colleagues (American Journal of Cardiology 1987;59:956-60). A further study reported in the abstract below shows that even after adjustment for height there remains an independent strong positive association with body weight. Thus obese subjects have unduly large and heavy left ventricles. These data raise questions about what should be regarded as "normal" and what as "hypertrophy". Perhaps more important is the question whether the increased left ventricular mass in obese subjects is a cause of excess mortality.

MJ DAVIES

\section{The impact of obesity on left ventricular mass and geometry: The Framingham Heart Study}

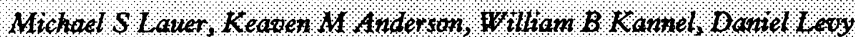

Objective. . T o determine the refationship of varying degrees of obesity wih left veniricular mass and geometry.

Design, Survey

Setting- Population-based , epideniologic study.

Participants and Methods, M-node echocardiograms, which were adequate for estimation of left ventriculat mass, were obtained in 3922 healthy participants of the Pramingham Heart Study, Measured height and wetght were used to calculate body-mass matex, a measure of obesity,

Results. - Body-mass index was strongly correlated with left ventricular mass, After ad justing for age and biodd pressine, body - arass index remained a strong independent otedictor of left ventricular mass, left ventrictilar wall thicloness, ane left ventricular internal dimension $(P<0.01$ for aft). Body mass index was associaled with prevalence of echocardiographic left ventricular lyppertrophy, patticularly in subjects with a body mass Index exceeding $30 \mathrm{~kg} / \mathrm{m}$ ? .

Conclusions, Othesity is significantly cortelated whith left veatricular mass, even after controlling for age and blood pressure. The increase in left ventricular orass issociated with increasing adiposity reflects increases in both left ventricular wall thickness and left ventricular internal dimension. JAMA $1091,266: 231=36$ 